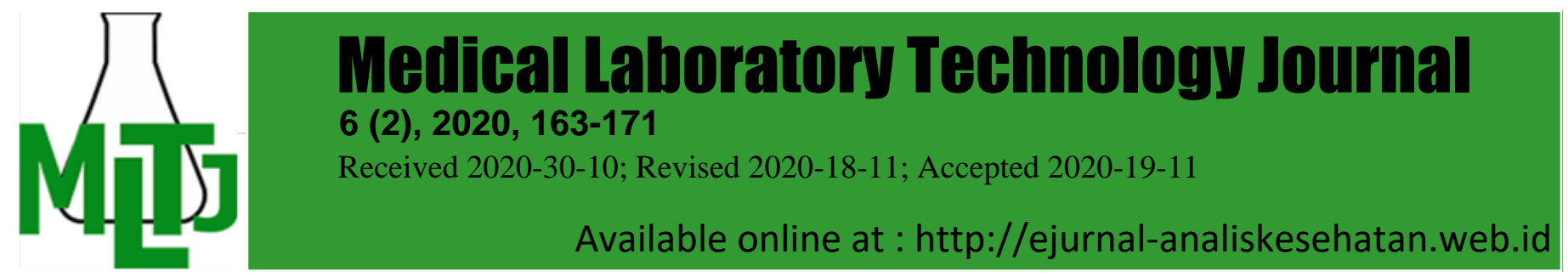

\title{
Evaluation of Toxoplasma gondii IgM and IgG Seropositivities in Serum Samples Sent from Pediatric and Adult Hematology/Oncology Outpatient Clinics
}

\author{
${ }^{*}$ Ayfer Bakır ${ }^{1}$, Mustafa Guney² \\ ${ }^{1}$ University of Health Sciences, Gulhane Training and Research Hospital, \\ Department of Medical Microbiology, Ankara, Turkey. ${ }^{2}$ University of Health Sciences, \\ Gülhane Faculty of Medicine, Department of Medical Microbiology, Ankara, Turkey. \\ *Email: dr.ayfer.bakir@gmail.com \\ DOI: $10.31964 / \mathrm{mltj} . v 6 \mathrm{i} 2.342$
}

\begin{abstract}
Despite its mild course in immunocompetent individuals, toxoplasmosis may have a more painful period in immunosuppressed patients such as hematology and oncology patients. This information needs to be known so that it becomes a consideration for inclusion in the standard test protocol, especially in patients diagnosed with leukemia and lymphoma. Serum samples sent from pediatric and adult hematology/oncology outpatient clinic to the Microbiology Laboratory between January 2017 and August 2019 were analyzed using Architect Toxo IgG and IgM Reagent Kit chemiluminescent microparticulate enzyme immunoassay method on Architect system. A total of 673 patient samples belonging to 131 pediatric patients and 542 adult patients analyzes in the study. The study group's median age was 29 (range: $0-83$ ), and $53.5 \%$ of them were male. While Toxoplasma gondii IgM positivity was $8 \%$, IgG positivity was $28.7 \%$. Toxoplasma gondii IgG seropositivities in male and female patients were $27.2 \%$ and $30.4 \%$ respectively $(\mathrm{p}=0.44)$. Toxoplasma gondii IgM seropositivities in pediatric and adult patients were $6.9 \%$ and $8.3 \%$ respectively, and IgG seropositivities were $24.4 \%$ and $29.7 \%$ ( $p=0.78$ and $p=0.46$ respectively). $T$. gondii IgM positivity was found as $8 \%$ and IgG positivity as $28.7 \%$ in the study group. In conclusion, data obtained from the study were in compliance with both domestic and foreign data and the highest rate of $\operatorname{lgM}$ and $\lg G$ seropositivity was found in patients with lymphoma. Given the severe infection in this population, we recommend that serologic testing for toxoplasma be added to routine testing when this group of patients diagnosis.
\end{abstract}

Keywords: ELISA; hematological malignancy; oncology; seropositivity; Toxoplasma gondii.

\section{INTRODUCTION}

Toxoplasmosis is one of the most common parasitic infections caused by Toxoplasma gondii ( $T$. gondii), a protozoan (Chintakuntlawar et al. 2015). T. gondii generally infects warm-blooded vertebrates and humans (Su et al., 2012).

T. gondii may transmit by consuming raw or underdone meat contaminated with parasite tissue cysts (Pereira, Franco \& Leal, 2012). The infection of a woman who infects $T$. gondii during or just before the pregnancy may transmit to the intrauterine fetus. It may also transmit by infected blood transfusion and organ transplant from a $T$. gondii positive donor. Besides, people dealing with infected blood at the laboratory are also at risk (CDC, 2020).

One-third of the world population infects with latent toxoplasmosis. Its incidence is higher in underdeveloped countries compared to developed countries Corresponding Author: Ayfer Bakır

University of Health Sciences, Gulhane Training and Research Hospital, Department of Medical Microbiology, General Dr. Tevfik Sağlam Street, Etlik, Ankara, Turkey.

E-mail: dr.ayfer.bakir@gmail.com 
(Chintakuntlawar et al., 2015). Seropositivity of $T$. gondii differs in different regions of the world depending on a socioeconomic level, climate, environmental factors, age, and contact with animals (Aşcı \& Akgün, 2015). Latin America, Eastern and Middle Europe, Middle Eastern, and South-Eastern Asia, and Africa regions have the highest prevalence (Chintakuntlawar et al., 2015).

Primary infections caused by $T$. gondiiare generally asymptomatic or characterized by non-specific symptoms. The parasite converts into cyst form on the host and creates the latent chronic disease (Lappalainen \& Hedman, 2004). Contrary to the mild course of toxoplasmosis in immunocompetent individuals, it may have a prognostic approach resulting in more severe disease clinics threatening the life of immunosuppressed patients (Israelski \& Remington, 1993). Therefore, immunosuppressive patients such as patients with hematological malignancy (especially patients with lymphoma), patients who underwent bone marrow or solid organ transplant (including heart, lung, liver, or kidney), and patients with AIDS directly targeting the immune system are high-risk groups in terms of toxoplasmosis (Montoya, 2002).

Toxoplasmosis is usually diagnosed with serological tests. These tests are generally enzyme immunoassay or immunofluorescence-based tests (Botein et al., 2019). T. gondii immunoglobulin $\mathrm{G}(\mathrm{IgG})$ antibodies investigate to determine whether an individual has experienced $T$. gondii or not. The time of infection, diagnostic methods, and avidity tests investigating T. gondii immunoglobulin M ( $\operatorname{lgM})$ antibodies are used primarily for pregnant women (CDC, 2020).

Toxoplasmosis is a fundamental problem as hematology and oncology patients with toxoplasmosis both are immunosuppressed and often need a blood transfusion as a result of the nature of their diseases. It has a more severe prognostic course and causes serious sequela in these patient groups. There are very few studies on the seropositivity of $T$. gondii in the hematology/oncology patient population in our country.

Studies on T. gondii seropositivity rates in Turkey observe to limit with the general population and pregnant women (Çiçek et al., 2012; Kasap et al., 2017). The number of seropositivity studies in hematology/oncology patients has limits in the last ten years. This study aimed to determine whether T. gondii in hematologic and oncologic diseases was at alarming seropositivity rates or not. It also sought to obtain information about the necessity to investigate anti-Toxoplasma antibodies, especially when patients were diagnosed with leukemia and lymphoma.

\section{MATERIALS AND METHOD}

The Ethics Committee approved this study of Gulhane Training and Research Hospital at the University of Health Sciences in Turkey (reference number: 2019/19/419). This study performs as a retrospective, cross-sectional, and descriptive survey at Ankara Gulhane Training and Research Hospital in Turkey. A total of 673 patients' serum samples sents from pediatric and adult hematology/oncology outpatient clinics to Microbiology Laboratory between January 2017 and August 2019. Repeated examinations belonging to the same patient excludes from the study, and the first evaluation results consider. Serum samples were analyzed using Architect Toxo IgG and IgM Reagent Kit (Abbott, Germany) with a chemiluminescent microparticulate enzyme immunoassay method on the Architect system (Architect i2000SR, Abbott Diagnostics, USA). The results assess according to the assessment criteria of the kits. According to the commercial equipment, index values accepted as follows: $<0.5$ was index negative, and $\geq 0.6$ was index positive for toxoplasma IgM 
antibodies and $<1.6 \mathrm{IU} / \mathrm{ml}$ was negative, and $\geq 3.0 \mathrm{IL} / \mathrm{ml}$ was positive for toxoplasma IgG antibodies. Data analysis performs with SPSS 25 (SPSS Inc, Chicago, IL, USA) software program. Compliance of the variables with the normal distribution assesses with visual methods (histogram and probability plots) and the Kolmogorov-Smirnov test. Quantitative variables compared with Student T-test or Mann Whitney U test and qualitative variables with Pearson Chi-Square or Fisher Exact tests. P values of $<0.05$ accepted as statistically significant.

\section{RESULTS AND DISCUSSION}

Median age of the patients (131 children and 542 adults; 673 patients in total) included in the study was 29 (range $=0-83$ ) and $53.5 \%$ of 673 patients were male. Median ages of $T$. gondii negative and positive patients were 28 (range $=0-83$ ) and 33 (range $=0-80)$ respectively $(\mathrm{p}=0.04)$. While $T$. gondii IgM positivity was $8 \%(54 / 673)$ lgG positivity was $28.7 \%(193 / 673)$. T. gondii IgG seropositivities in male and female patients were $27.2 \%(98 / 360)$ and $30.4 \%(95 / 313)$ respectively $(p=0.44)$.

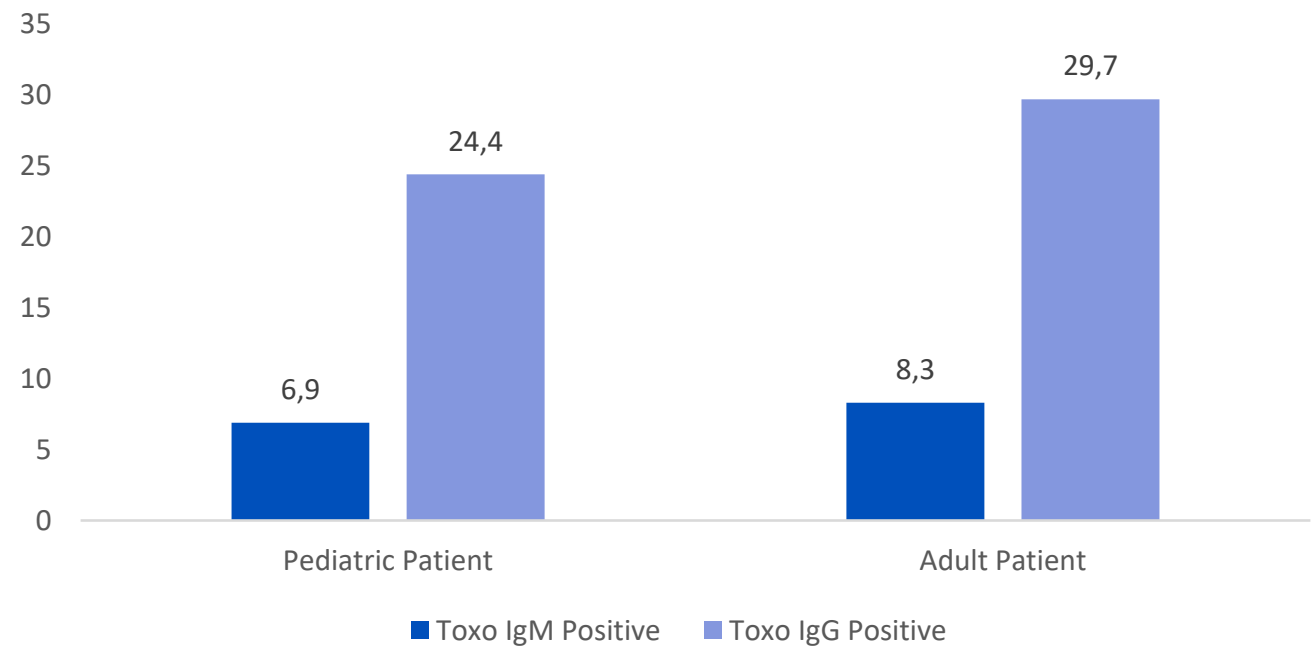

Figure 1. Toxo IgM and IgG Seropositivity Rates of Pediatric and Adult Hematology/Oncology Patients

Table 1. Toxoplasma Positivity Rates According to the Age Groups

\begin{tabular}{lcccc}
\hline \multirow{2}{*}{$\begin{array}{l}\text { Age } \\
\text { groups }\end{array}$} & $\begin{array}{c}\text { Negative } \\
\mathrm{n}(\%)\end{array}$ & $\begin{array}{c}\text { Poxo IgM } \\
\mathrm{n}(\%)\end{array}$ & $\begin{array}{c}\text { Borderline } \\
\mathrm{n}(\%)\end{array}$ & \multirow{2}{*}{ * $\mathrm{p}$-value } \\
\hline $0-18$ & $122(93.1)$ & $9(6.9)$ & - & 0.89 \\
$19-39$ & $336(92.3)$ & $27(7.4)$ & $1(0.3)$ & \\
$40-59$ & $110(90.2)$ & $12(9.8)$ & - & \\
$\geq 60$ & $50(89.3)$ & $6(10.7)$ & - & \\
& & Toxo IgG & & \\
\hline $0-18$ & $97(74)$ & $32(24.4)$ & $2(1.5)$ & \\
$19-39$ & $251(69)$ & $105(28.8)$ & $8(2.2)$ & \\
$40-59$ & $79(64.8)$ & $41(33.6)$ & $2(1.6)$ & \\
$\geq 60$ & $41(73.2)$ & $15(26.8)$ & - & \\
\hline
\end{tabular}

${ }^{*} p$ value, Pearson Chi-Square 
T. gondii IgM seropositivities in pediatric and adult patients were $6.9 \%(9 / 131)$ and $8.3 \%(45 / 542)$ respectively and IgG seropositivities were $24.4 \%(32 / 131)$ and $29.7 \%(161 / 542)$ (Figure 1$)(p=0.78$ and $p=0.46$ respectively). According to the age groups, the highest IgM seropositivity rate was found in the age group of 60 years and above at a rate of $10.7 \%(6 / 56)$, and the highest IgG seropositivity found in the age group of $40-59$ years at a rate of $33.6 \%(41 / 122)(p=0.81$ and $p=0.73$ respectively) (Table 1).

Table 2. Toxoplasma Seropositivity Rates in Pediatric and Adult Hematology/Oncology Outpatient Clinics

\begin{tabular}{lccccc}
\hline & \multicolumn{2}{c}{ Pediatric Patients } & \multicolumn{2}{c}{ Adult Patients } & \\
& $\begin{array}{c}\text { Hematology } \\
\mathrm{n}(\%)\end{array}$ & $\begin{array}{c}\text { Oncology } \\
\mathrm{n}(\%)\end{array}$ & $\begin{array}{c}\text { Hematology } \\
\mathrm{n}(\%)\end{array}$ & $\begin{array}{c}\text { Oncology } \\
\mathrm{n}(\%)\end{array}$ & p-value \\
\hline Toxo IgG & & & & \\
Negative & $64(70.3)$ & $24(75)$ & $312(68.4)$ & $68(72.3)$ & 0.18 \\
Positive & $27(29.7)$ & $6(18.8)$ & $134(29.4)$ & $26(27.7)$ & \\
Borderline & - & $2(6.3)$ & $10(2.2)$ & - & \\
Toxo IgM & & & & & \\
Negative & $88(96.7)$ & $27(84.4)$ & $420(92.1)$ & $83(88.3)$ & 0.28 \\
Positive & $3(3.3)$ & $5(15.6)$ & $35(7.7)$ & $11(11.7)$ & \\
Borderline & - & - & $1(0.2)$ & - & \\
\hline${ }^{*}$ p-value, Pearson Chi-Square & & & &
\end{tabular}

Table 3. Toxo IgM and Toxo IgG Serology Results of Hematology/Oncology Patients According to the Diagnostic Groups

\begin{tabular}{lcccccc}
\hline \multirow{2}{*}{ Diagnosis } & $\begin{array}{c}\text { Negative } \\
\mathrm{n}(\%)\end{array}$ & $\begin{array}{c}\text { Poxitive } \\
\mathrm{n}(\%)\end{array}$ & $\begin{array}{c}\text { Borderline } \\
\mathrm{n}(\%)\end{array}$ & $\begin{array}{c}\text { Negative } \\
\mathrm{n}(\%)\end{array}$ & $\begin{array}{c}\text { Positive } \\
\mathrm{n}(\%)\end{array}$ & $\begin{array}{c}\text { Borderline } \\
\mathrm{n}(\%)\end{array}$ \\
\hline $\begin{array}{l}\text { Diseases of } \\
\text { blood/blood- } \\
\text { forming } \\
\text { organs } \\
(\mathrm{n}=204)\end{array}$ & $187(91.7)$ & $16(7.8)$ & $1(0.5)$ & $142(69.6)$ & $56(27.4)$ & $6(3)$ \\
\hline $\begin{array}{l}\text { Bone morrow } \\
\text { donor } \\
(n=165)\end{array}$ & $152(92.1)$ & $13(7.9)$ & - & $108(65.5)$ & $56(33.9)$ & $1(0.6)$ \\
\hline $\begin{array}{l}\text { Acute } \\
\text { lymphadenitis } \\
(n=108)\end{array}$ & $102(94.4)$ & $6(5.6)$ & - & $82(75.9)$ & $25(23.1)$ & $1(1)$ \\
\hline $\begin{array}{l}\text { Malignancy } \\
(n=134)\end{array}$ & $119(88.8)$ & $15(11.2)$ & - & $96(71.6)$ & $37(27.6)$ & $1(0.8)$ \\
\hline $\begin{array}{l}\text { Other* } \\
(n=62)\end{array}$ & $58(93.5)$ & $4(6.5)$ & - & $40(64.5)$ & $19(30.7)$ & $3(4.8)$ \\
\hline
\end{tabular}

${ }^{*}$ Other: Fever, Respiratory Tract Infection, pain, general examination, pregnancy, emboli/thrombosis, habitual abortus, hypogammaglobulinemia, hypothyroidism

Toxo IgG seropositivity mostly found in the serum samples sent from pediatric $(29.7 \%)$ and adult (29.4\%) hematology outpatient clinics (Table 2). Toxo IgM 
seropositivity mostly found in patients diagnosed with malignancy (11.4\%), and Toxo IgG positivity primarily found in bone morrow donors (33.9\%) (Table 3). The highest Toxo IgM and IgG seropositivity in patients diagnosed with malignancy was found in patients with lymphoma (Table 4).

Table 4. Toxo IgM and IgG Seropositivity Rates in Patients Diagnosed with a Malignancy

\begin{tabular}{|c|c|c|c|c|c|c|}
\hline \multirow[b]{2}{*}{ Malignancy } & \multicolumn{3}{|c|}{ Toxo IgM } & \multicolumn{3}{|c|}{ Toxo IgG } \\
\hline & $\begin{array}{c}\text { Negative } \\
\mathrm{n}(\%)^{*}\end{array}$ & $\begin{array}{l}\text { Positive } \\
\mathrm{n}(\%)^{*}\end{array}$ & $\begin{array}{l}\text { Borderline } \\
\mathrm{n}(\%)^{*}\end{array}$ & $\begin{array}{c}\text { Negative } \\
\mathrm{n}(\%)^{\star}\end{array}$ & $\begin{array}{c}\text { Positive } \\
\mathrm{n}(\%)^{*}\end{array}$ & $\begin{array}{c}\text { Borderline } \\
\mathrm{n}(\%)^{*}\end{array}$ \\
\hline $\begin{array}{l}\text { Hematological } \\
\text { malignancy }\end{array}$ & $40(90.9)$ & $4(9.1)$ & & $32(72.7)$ & $11(25)$ & $1(2.3)$ \\
\hline ALL & 12 (100) & - & - & $8(66.6)$ & $4(33.4)$ & - \\
\hline AML & $6(75)$ & $2(25)$ & - & 7 (87.5) & $1(12.5)$ & - \\
\hline $\begin{array}{l}\text { Multiple } \\
\text { myeloma }\end{array}$ & $21(95.5)$ & $1(4.5)$ & - & $17(77.2)$ & $4(18.1)$ & $1(4.5)$ \\
\hline $\begin{array}{l}\text { Myelodysplastic } \\
\text { syndrome }\end{array}$ & $1(50)$ & $1(50)$ & - & - & $2(100)$ & - \\
\hline Lymphoma & $22(84.6)$ & $4(15.4)$ & & $17(65.3)$ & 9 (34.7) & - \\
\hline $\begin{array}{l}\text { Hodgkin } \\
\text { disease }\end{array}$ & $10(83.3)$ & $2(16.7)$ & - & $10(83.3)$ & $2(16.7)$ & - \\
\hline $\mathrm{NHL}$ & $12(85.7)$ & $2(14.3)$ & - & $7(50)$ & $7(50)$ & - \\
\hline $\begin{array}{l}\text { Organ } \\
\text { malignancy }\end{array}$ & $55(88.7)$ & 7 (11.3) & & $45(72.5)$ & $17(27.5)$ & - \\
\hline Brain & $3(75)$ & $1(2)$ & - & $2(50)$ & $2(50)$ & - \\
\hline Ovary & $3(75)$ & $1(25)$ & - & $3(75)$ & $1(25)$ & - \\
\hline Testis & 45 (93.8) & $3(6.2)$ & - & 35 (72.9) & $13(27.1)$ & - \\
\hline $\begin{array}{l}\text { Connective and } \\
\text { soft tissue }\end{array}$ & $4(66.6)$ & $2(33.4)$ & - & $5(83.3)$ & $1(16.7)$ & - \\
\hline $\begin{array}{l}\text { Bone and } \\
\text { cartilage }\end{array}$ & $2(100)$ & - & - & $2(50)$ & $2(50)$ & - \\
\hline Total & $119(89)$ & $15(11)$ & - & $96(72)$ & $37(27.6)$ & $1(1.4)$ \\
\hline
\end{tabular}

${ }^{*}$ Line percentage; NHL, Non-Hodgkin lymphoma; ALL, Acute lymphocytic leukemia;

AML, Acute myelocytic leukemia

T. gondii infection is common worldwide. While the term toxoplasmosis defines the clinical or pathological disease caused by $T$. gondii, the definition of chronic or latent $T$. gondii infection use for asymptomatic primary infection or parasite permanence on tissues (Montoya, 2002). This latent $T$. gondii infection becomes a significant cause of encephalitis, spontaneous abortus, mental retardation, ocular disease, and death, especially in immunosuppressive patients, hematology-oncology patients (Abdel Malek et al., 2018). The infection causes severe pathological changes in fetuses, especially during the intrauterine period and in immunosuppressed patients (Khan \& Noordin, 2020). Besides, T. gondii infection plays a role in developing various disorders such as liver cirrhosis, epilepsy, and even schizophrenia. Recently, reports have revealed a possible relationship between $T$. gondii infection and cancer risk. Several studies on that issue have given contradictory results for leukemia (Huang et al., 2016). 
On the other hand, while toxoplasmosis can frequently provide diagnosis serologically in immunocompetent patients, it can generally be diagnosed with the combination of several disciplines such as pathology, microbiology, radiology, and clinics since serological diagnosis do not give accurate results in immunosuppressive patients such as hematology, oncology, and organ transplant patients (Botein et al., 2019). This matter suggests that there must be more serological data to obtain.

T. gondii seroprevalence ranges from $15 \%$ to $85 \%$ in different regions of Turkey (Aşcı \& Akgün, 2015). Prevalence rates report to be $10-30 \%$ in North America, Southeast Asia, Northern Europe, and Sahelian countries of Africa, 30-50\% in Eastern and Southern Europe and higher in Latin America and tropical African countries (Robert-Gangneux \& Dardé, 2012).

Studies performed in Turkey are mostly related to women at their fertile periods and the pregnant population (Çiçek et al., 2012; Kasap et al., 2017). Seroprevalence regionally differs between $18.8 \%$ and $68.9 \%$ in these studies (Senoglu et al., 2018; Duran et al., 2017; Okyay et al., 2013). The highest seroprevalence rates in Turkey report in the Southeastern Anatolia Region (68.9\%), Eastern Anatolia (63\%), and Mediterranean Region (57\%). Toxo IgG positivity rates in studies performed in the Central Anatolia Region founders between 26.9\% and 36\% (Senoglu et al., 2018; Duran et al., 2017; Okyay et al., 2013; Malatyalı et al., 2019). In this study, T. gondii lgG seropositivity rate in hematology/oncology patients was $28.7 \%$. Our results were consistent with regional data. The difference in local seroprevalence rates varies depending on geographical factors, climatic characteristics, hygienic conditions, dietary habits, and socioeconomic factors (Akduman Alasehir \&Yaman, 2018).

Although the seropositivity rate was higher in adult patients than in pediatric patients, the difference was not significant (Figure 1). Similarly, its report in studies performed in Turkey that toxoplasma seroprevalence increases by age (Kaplan et al., 2014).21 In several worldwide studies, toxoplasmosis seroprevalence in women report at higher rates (Wang et al., 2017). Although the seropositivity rate was higher in the female gender in numerical value, the data were not statistically significant.

$T$. gondii lgG seropositivity was the highest in serum samples sent from pediatric and adult hematology outpatient clinics at the rates of $29.7 \%$ and $29.4 \%$, respectively (Table 2 ). When the data obtained from the information system of the hospital evaluated $T$. gondii IgG positivity found to be the highest in bone marrow donors (34\%). In comparison, positivity rates in patients with blood and blood-forming disease and patients with malignancy were $28 \%$ and $27 \%$, respectively, and these rates were lower compared to bone marrow donors (Table 3). This difference suggests that bone marrow donors have been treated more sensitively than hematology and oncology patients in terms of $T$. gondii $\operatorname{lgM}$ and $\lg \mathrm{G}$ seropositivity during donor selection and accordingly that more $T$. gondii $\lg M$ and $\lg G$ requested. In the study, the highest rate of $T$. gondii IgM and IgG seropositivity founds in patients diagnosed with lymphoma (Table 4). T. gondii is an important opportunistic pathogen in the case of immunosuppression (CD4 T lymphocyte count: <200 cell/uL) in patients with AIDS (Wang et al., 2017).

In addition to various malignancy conditions such as leukemia, lymphoma, and myeloma, chemotherapy conditions may also reactivate toxoplasmosis (Kojima et al., 2010; Maciel et al., 2000). It revealed that transplant an infected organ to a seronegative receiver was more dangerous than the transmission of a non-infected organ to a seropositive receiver (Chehrazi-Raffle et al., 2015). When toxoplasma seroprevalence studies in Turkey considered seropositivity rates in hematology/oncology patients, this study was consistent with regional results. 
However, it should not forget that the results found in immunosuppressed patients such as patients with HIV/AIDS, patients with cancer, and organ transplant receivers will be lower than the actual prevalence due to their insufficient production of specific antibodies (Saadatnia \& Golkar, 2012). A routine serological screening test recommends in patients with immunodeficiency in regions where $T$. gondii is endemic (Wang et al., 2017). Our study's limitations were that Toxo IgM seropositive patients could not follow up clinically because it was a retrospective and cross-sectional study.

\section{CONCLUSION}

Data obtained from the study in compliance with domestic and foreign data with the highest $\operatorname{lgM}$ and $\lg G$ seropositivity rates found in patients with lymphoma. Hematology and oncology patients are immunosuppressive patients with positive results due to toxoplasmosis reactivation are at risk for reactivation. Patients with negative effects are at stake in terms of primary infection. Their results are pseudonegative. They cannot give sufficient immunological response, so toxoplasmosis in such patients should always be up to date as an issue to consider.

\section{CONFLICT OF INTEREST}

The authors have no potential conflicts of interest regarding this study.

\section{REFERENCE}

Abdel Malek R, Wassef R, Rizk E, Sabry H, Tadros N, Boghdady A. (2018).Toxoplasmosis an Overlooked Disease: Seroprevalence in Cancer Patients. Asian Pac J Cancer Prev, 19(7):1987-1991.

Akduman Alasehir E, Yaman G. (2018) Evaluation of Toxoplasma gondii Seroprevalence Among Women of Childbearing Age Group in Istanbul. Okmeydanı Tıp Dergisi, 34(2), 158-162.

Aşcı Z, Akgün S. (2015). The Evaluation of Toxoplasma gondii (T.gondii) Serology Results Among Cases Who Admitted to the Serology Laboratory of a Hospital in Afyon City. Turkiye Parazitol Derg, 39(1): 9-12.

Botein, E.F., Darwish, A., El-Tantawy, N.L., El-Baz, R., Eid, M.I., \& Shaltot, A.M. (2019). Serological and molecular screening of umbilical cord blood for Toxoplasma gondii infection. Transplant infectious disease : an official journal of the Transplantation Society, 21(4), e13117.

CDC-Toxoplasmosis [Internet]. [cited 2020 Jan 2]. Available from: https://www.cdc.gov/parasites/toxoplasmosis/index.html.

Chehrazi-Raffle, A., Luu, M., Yu, Z., Liou, F., Kittleson, M., Hamilton, M., \& Kobashigawa, J. (2015). Toxoplasma gondii Serology and Outcomes After Heart Transplantation: Contention in the Literature. Transplantation proceedings, 47(6), 1949-1953.

Chintakuntlawar, A., Kidd, M., Al-Kali, A., Wilson, W., \& Thompson, C.A. (2015). Toxoplasmosis in patients with hematologic malignancies. Leukemia \& lymphoma, 56(2), 536-538.

Çiçek, A.Ç., Duygu, F., İnakçı, İ.H., Boyar, N., \& Boyar, İ.H. (2012). Investigation of Toxoplasma gondii antibodies with ELISA among women of childbearing age in Şanlıurfa province: A three years evaluation. Journal of Clinical and Experimental Investigations, 3(1), 61-65.

Duran, I.., Nazik, S., Nazik, H., \& Duran, Ş. (2017). Evaluation of toxoplasma and rubella seropositivity in pregnancy. Balıkesir Med J, 1(1), 22-25.

Huang, Y., Huang, Y., Chang, A., Wang, J., Zeng, X., \& Wu, J. (2016). Is Toxoplasma 
Gondii Infection a Risk Factor for Leukemia? An Evidence-Based Meta-Analysis. Medical science monitor : international medical journal of experimental and clinical research, 22, 1547-1552.

Israelski, D.M., \& Remington, J.S. (1993). Toxoplasmosis in the non-AIDS immunocompromised host. Current clinical topics in infectious diseases, 13, 322-356.

Kaplan M, Bayar Z, Aslan R, Arı N, Özavcı H, Aşçı Toraman Z. (2014) Toxoplasma Seropositivity in Patients Admitted to the Central Laboratory of Firat University Hospital with the Suspicion of Toxoplasmosis. F.Ü.Sağ.Bil.Tıp Derg, 28(1): 21 24.

Kasap, B., Öner, G., Küçük, M., Öztürk Turhan, N., Akın, M.N., Arıkan, S., \& Dirgen Chaylak, S. (2017). Evaluation of toxoplasmosis, rubella, cytomegalovirus and hepatitis prevalence of pregnant women in Muğla. Tepecik Eğitim ve Araştırma Hastahanesi Dergisi, 27, 31-36.

Khan, A.H., \& Noordin, R. (2020). Serological and molecular rapid diagnostic tests for Toxoplasma infection in humans and animals. European journal of clinical microbiology \& infectious diseases : official publication of the European Society of Clinical Microbiology, 39(1), 19-30.

Kojima, M., Nakamura, N., Murayama, K., Igarashi, T., Matsumoto, M., Matsuda, H., Masawa, N., Miura, I., \& Morita, Y. (2010). Reactive lymphoid hyperplasia with giant follicles associated with a posttherapeutic state of hematological malignancies. A report of eight cases. Tumori, 96(1), 143-148.

Lappalainen M, Hedman K. (2004). Serodiagnosis of toxoplasmosis. The impact of measurement of IgG avidity. Ann Ist Super Sanita, 40(1), 81-88.

Maciel, E., Siqueira, I., Queiroz, A.C., \& Melo, A. (2000). Toxoplasma gondii myelitis in a patient with adult T-cell leukemia-lymphoma. Arquivos de neuro-psiquiatria, 58(4), 1107-1109.

Malatyalı, E., Yıldız, I.., Tileklioğlu, E., Ertabaklar, H., \& Ertuğ, S. (2019). Retrospective Analysis of Toxoplasma gondii Serology Results from Adnan Menderes University Faculty of Medicine Parasitology Laboratory from 2007 to 2017. Türkiye Parazitolojii Dergisi, 43(1), 1.

Montoya J.G. (2002). Laboratory diagnosis of Toxoplasma gondii infection and toxoplasmosis. The Journal of infectious diseases, 185 Suppl 1, S73-S82.

Pereira KS, Franco RM, Leal DA. (2010). Transmission of toxoplasmosis (Toxoplasma gondii) by foods. Adv Food Nutr Res, 60,1-19.

Robert-Gangneux F, Dardé M.L. (2012). Epidemiology of and diagnostic strategies for toxoplasmosis. Clin Microbiol Rev, 25(2), 264-296.

Saadatnia, G., \& Golkar, M. (2012). A review on human toxoplasmosis. Scandinavian journal of infectious diseases, 44(11), 805-814.

Senoglu, S., Yesilbag, Z., Aydin, Ö.A., Karaosmanoglu, H.K., \& Yasar, K.K. (2018). HIV/AIDS Hastalarinda Toxoplasma gondu IgG Seroprevalansi/Toxoplasma gondu IgG Seroprevalence in Patients with HIV/AIDS. Turkish Journal of Parasitology, 42(3), 175-180.

Su, C., Khan, A., Zhou, P., Majumdar, D., Ajzenberg, D., Dardé, M.L., Zhu, X.Q., Ajioka, J.W., Rosenthal, B.M., Dubey, J.P., \& Sibley, L.D. (2012). Globally diverse Toxoplasma gondii isolates comprise six major clades originating from a small number of distinct ancestral lineages. Proceedings of the National Academy of Sciences of the United States of America, 109(15), 5844-5849.

Okyay, A.G., Karateke, A., Yula, E., Inci, M., Şilfeler, D.B., Motor, V.K., ... \& Okur, M. (2013) Seroprevalance of Toxoplasma IgG Among Pregnant Women in The 
Province of Hatay and Contributıon of Avidıty Test to The Diagnose. Journal of Turkish Society of Obstetric and Gynecology, 10, 160-164.

Wang, Z.D., Liu, H.H., Ma, Z.X., Ma, H.Y., Li, Z.Y., Yang, Z.B., Zhu, X.Q., Xu, B., Wei, F., \& Liu, Q. (2017). Toxoplasma gondii Infection in Immunocompromised Patients: A Systematic Review and Meta-Analysis. Frontiers in microbiology, 8, 389. 